\title{
Promise of Higgs fails to save CERN collider
}

Alison Abbott, Munich

After eleven years and a nail-biting threemonth reprieve, the death knell for the Large Electron-Positron collider (LEP) in Geneva has finally been sounded.

Last week, Luciano Maiani, director-general of CERN, the European Laboratory for Particle Physics, rejected requests to keep the LEP running for another year, ruling that it should be dismantled early in the new year as planned.

The drama over the collider's future centred on the possible sighting by the LEP's detectors of the subatomic particle known as the Higgs boson (see Nature 408, 10; 2000). Showing that Higgs exists would bolster the Standard Model of particles and forces, and fulfil one of CERN's major missions.

The LEP had been granted a one-month extension to gather more data in support of the initial observation. As the probability that Higgs really had been seen fell at first, only to rise in the past few weeks, pressure grew on CERN's management to keep the LEP running for another year.

But that would have cost SFr100 million (US $\$ 57$ million) and delayed construction of the Large Hadron Collider (LHC), which will be powerful enough to confirm the Higgs if, as the LEP experiments suggest, it has a mass of 115 giga-electron volts.

High-energy physicists were unable to

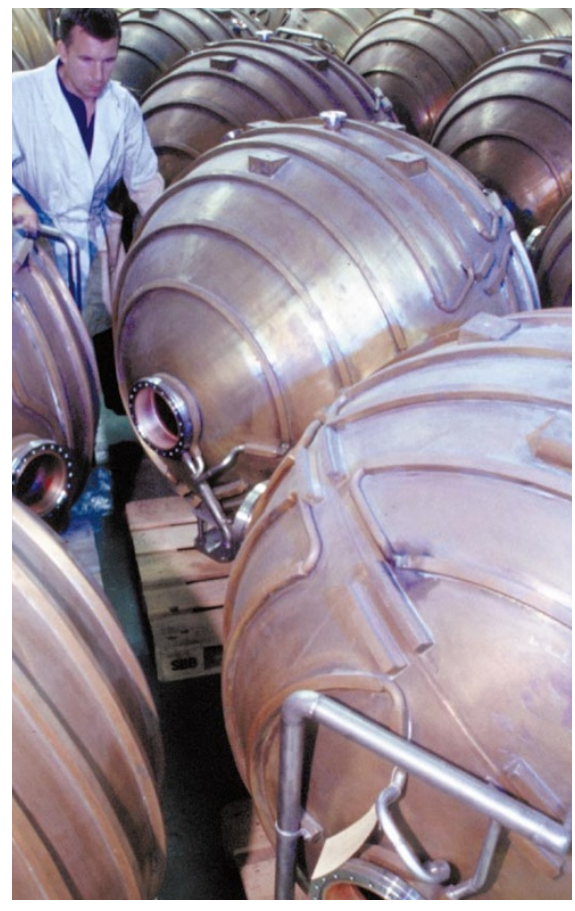

Switched off: accelerating cavities from the soon to be dismantled LEP collider in Geneva.

reach a consensus on whether the risk should be taken. The LEP scientific committee comprising LEP researchers, including some with experiments planned for the LHC, split
$50-50$ on whether to recommend the extension to CERN's research board. The board, whose job is to balance the whole of CERN's programme, also failed to reach a consensus. Even appeals to CERN's external Scientific Policy Committee drew an inconclusive response.

That left Maiani to bear responsibility for the decision. He took it, he says, not on a financial basis, "but on the basis of optimizing the overall scientific return of the laboratory".

"The conclusive discovery of Higgs within a year was not guaranteed and I thought it too risky to delay the LHC and distract the scientists who are going to run its experiments," he says. The LHC will, Maiani points out, let physicists study the properties of Higgs as well as just identifying it.

Roger Cashmore, CERN's research director, adds: "The best way forward for CERN is to proceed with the LHC as fast as possible. To change a good research programme you need a very strong set of arguments, which the committees did not supply."

But Chris Tully, one of the CERN physicists who worked on the Higgs search data, says the decision is "tragic for CERN". He believes CERN management has underplayed the strength of the evidence that the Higgs has been sighted.

inttp://public.web.cern.ch/Public

\section{Medical institute opens amid hopes of Kansas rebirth}

\section{Paul Smaglik, Kansas City}

The people of Kansas City, Missouri, are hoping that the official opening this month of the $\mathbf{\$ 2 0 0}$ million Stowers Institute for Medical Research will provide a springboard that will eventually transform the midwestern city into one of the nation's top life-science centres.

The institute - built by a married couple of wealthy cancer survivors who also donated its initial endowment of $\$ 515$ million, which could rise to $\$ 2$ billion reflects the growing influence of large-scale philanthropy on biomedical research in the United States.

The institute will not on its own revitalize Kansas City's research climate, as it will initially hire only four to six investigators a year, but it has already leveraged other activity aimed at doing just that.

Jim and Virginia Stowers, who made their fortune in the mutual-funds business in the city, say they ignored advice to spend their fortune on an institute in a more established centre of biomedical research on America's east or west coasts.
The advent of the institute has prompted the city to form a coalition of businesses, hospitals and universities called the Kansas City Area Life Sciences Institute (LSI). The coalition hopes that the high profile the new institute will bring to the area should help it meet its target of raising \$30 million a year locally over ten years. The LSI estimates that Kansas City's annual biomedical research effort, supported by the National Institutes of Health and other sources, could by then have expanded from $\$ 100$ million to $\$ 500$ million.

Bill Neaves, the president of the Stowers Institute, says he hopes that the LSI will help him to recruit top scientists. Before hiring anyone, he introduces them to scientists working at LSI coalition institutions, such as the Midwest Research Institute and the University of Missouri in Kansas City. Dual appointments and the chance to use facilities outside the Stowers Institute will attract talent, he believes.

Neaves has proceeded cautiously, under

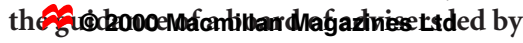
Doug Melton, chair of molecular and

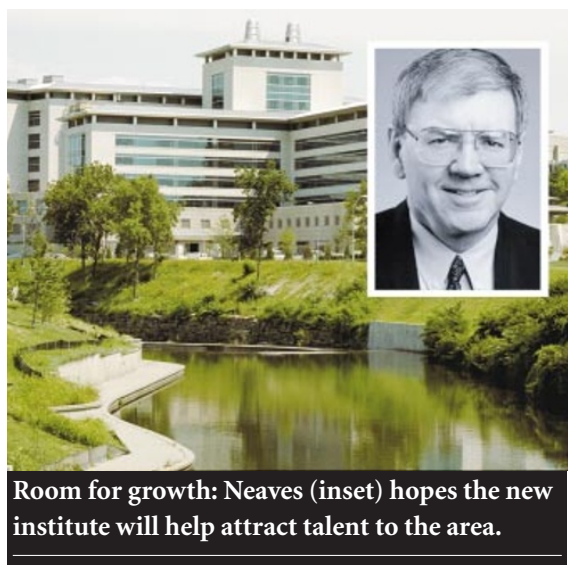

cellular biology at Harvard University. Neaves has so far hired four principal investigators, led by Robb Krumlauf, who previously ran the division of developmental neurobiology at Britain's National Institute for Medical Research at Mill Hill, London. “There's a danger in going too slow, but there is perhaps a greater danger of going too fast," says Neaves. http://www.stowers-institute.org 